\title{
Specific Parameters of the Perturbation Profile Differentially Influence the Vertical and Horizontal Head Accelerations During Human Whiplash Testing
}

\author{
Loriann M. Hynes, Natalie S. Sacher and James P. Dickey \\ Human Health and Nutr. Sci., University of Guelph \\ Canada
}

\section{Introduction}

Whiplash experiments using human subjects are important tools for evaluating biological response during collisions and can provide key insights into mechanisms of injury (Muhlbauer et al., 1999). Human experimentation, including whiplash-like perturbation testing, is essential to evaluate the kinematic, kinetic and electromyographic responses to enable mathematical models to predict the loads within neck structures (Choi \& Vanderby, 1999). Although some experimentation has been performed with staged collisions between actual automobiles (Welcher \& Szabo, 2001; Severy et al., 1955; Castro et al., 2001; Brault et al., 1998), more typically, human testing has been performed using experimental sleds (Dehner et al., 2007; Kumar et al., 2005b; Kumar et al., 2002; Muhlbauer et al., 1999; Siegmund et al., 2003; Kaneoka et al., 1999).

One limitation of sled testing is that the perturbation pulse varies from trial to trial due to the varying inertia between subjects, and the varying effective inertia as subjects respond differently to the perturbation. This is an important issue since certain properties of the crash pulse influence the risk of injury (Kullgren et al., 2000; Hynes \& Dickey, 2008). In order to address this limitation, some researchers have developed advanced test sleds that incorporate feedback-controlled linear motors to enable them to precisely control the properties of the perturbation pulse (Siegmund et al., 2005; Siegmund et al., 2004). This approach offers considerable advantage over spring (Magnusson et al., 1999), gravity (Kaneoka et al., 1999) and pneumatic (Kumar et al., 2002; Hernandez et al., 2005) driven sleds, yet it is still limited to simulating the anterior-posterior motion of vehicles. In contrast, research from experimental automobile collision studies that have used real vehicles has shown that the vehicle accelerations include substantial vertical accelerations (Severy et al., 1955; Welcher \& Szabo, 2001) due to factors such as the vehicle suspension and bumper height mismatch (Siegel et al., 2001).

Peak head acceleration is thought to be a key variable in whiplash, and typical and reproducible head/neck motion patterns have been observed in experiments with male ळे (Muhlbauer et al., 1999) and female (Dehner et al., 2007) volunteers; however, various О̊ published studies have observed different responses which cloud the interpretation of this

Source: Parallel Manipulators, New Developments, Book edited by: Jee-Hwan Ryu, ISBN 978-3-902613-20-2, pp. 498, April 2008, I-Tech Education and Publishing, Vienna, Austria 
body of research. For example, Kumar and colleagues (2005b; 2002; 2005a) consistently report that the peak magnitude of the head accelerations is less than the sled peak acceleration while others (Severy et al., 1955; Magnusson et al., 1999; Siegmund et al., 2003; Muhlbauer et al., 1999) report peak head accelerations that exceed the sled acceleration. Many human studies of whiplash-like perturbations have evaluated the horizontal component of the head acceleration response and have not fully appreciated the vertical component, although these two loading directions have different biological implications (Nightingale et al., 2000; Siegmund et al., 2001) and presumably different thresholds for injury. As notable exceptions, Siegmund et al. (2004) performed an in-depth analysis of the vertical and horizontal head accelerations in response to a series of increasing intensity perturbations, Welcher et al. (2001) evaluated the vertical and horizontal head accelerations of a single female subject exposed to 5 in-car collisions of differing severity, and Hernandez et al (2005) evaluated the displacement and acceleration responses of both female and male subjects exposed to two levels of perturbation. Siegmund et al. (2004) observed that high acceleration, high velocity perturbations consistently produced the largest muscle activations, head horizontal and vertical accelerations, head angular accelerations and velocities, and head angles compared to low acceleration, low velocity perturbations. Siegmund et al., (2004) and Welcher et al., (2001) both reported that the horizontal and vertical accelerations were highly correlated. Hernandez et al., (2005) observed that the angular head displacements as well as the rearward and forward angular head accelerations were somewhat increased in the fast case compared to the slow case. In addition, they noted that the males presented two times higher upward linear head acceleration than females in the unexpected condition. The purpose of this study was to investigate the relationship between the vertical and horizontal head accelerations during low velocity horizontal whiplash-like perturbations. Information about the relationship between the vertical and horizontal head accelerations during low velocity perturbations is essential to enable extrapolation of research findings from low velocity (non-injurious) perturbations to higher severity situations. We have used a commercial parallel robot as a feedback-controlled motion platform to provide the different perturbation pulses.

\section{Methods}

Permission for this study was obtained from the University of Guelph Research Ethics Board and written consent was obtained from all subjects. Seventeen subjects underwent a cervical spine orthopaedic examination performed by a Certified Athletic Therapist, as well as questionnaire screening, to ensure they were free of any neck pain and/or obvious neck pathology. We excluded subjects who reported being involved in a car accident in the previous five years.

A robotic platform (R2000, PRSCo, New Hampshire, USA) was used to apply the lowvelocity whiplash-like perturbations. The accuracy of the robot is $\pm 0.001 \mathrm{~mm} \pm 0.001$ degrees in Cartesian space, permitting precisely controlled and repeatable perturbations. All robot motion was restricted to the posterior-anterior direction. Two specific robotic displacement profiles were generated (Figure 1). One profile reflected the kinematics of a spring-powered experimental sled with a peak velocity of $2.14 \mathrm{kph}$ and peak acceleration of $0.41 \mathrm{~g}$ termed "mild", which was generated by integrating the published acceleration pulse (Figure 3, Magnusson et al., 1999). The second profile had a higher peak acceleration (0.94g), peak velocity (3.06 kph), and a shorter time to peak acceleration, and was termed "moderate". 


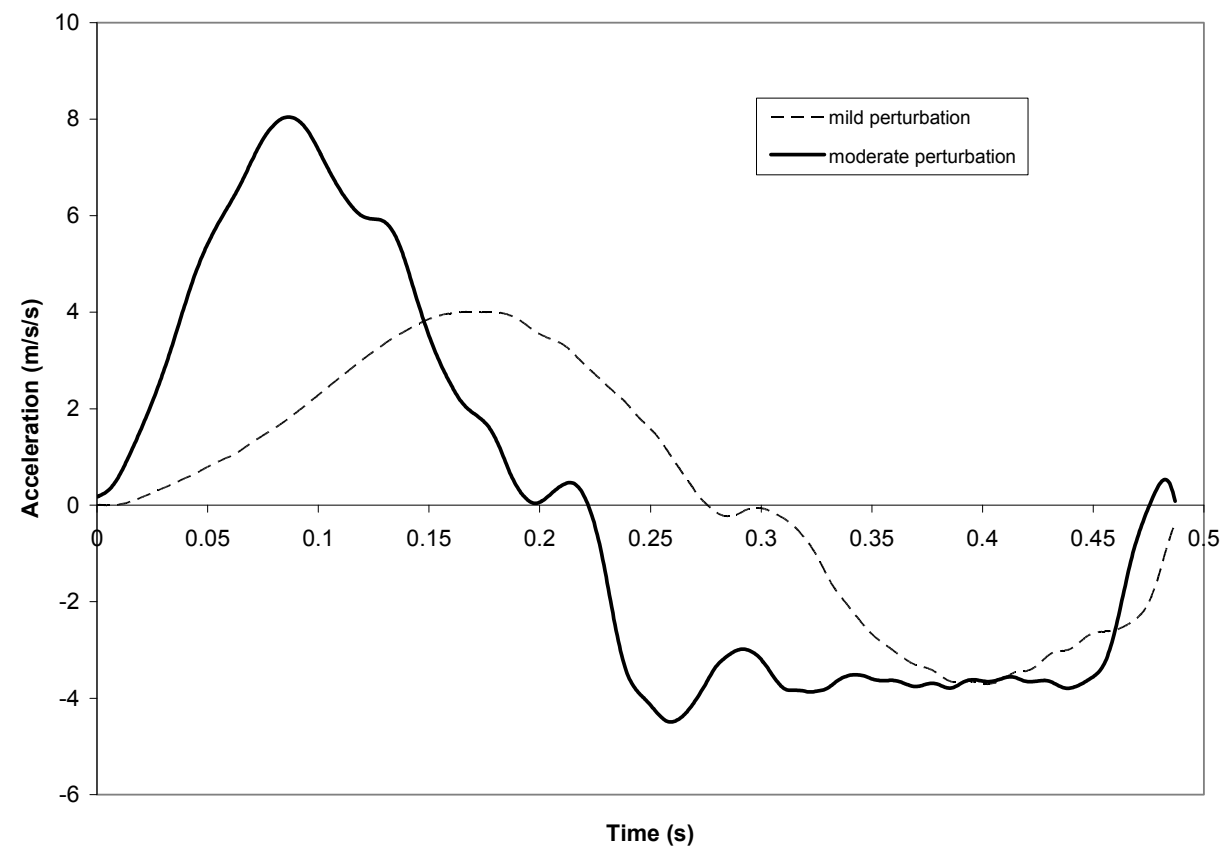

Fig. 1. Time course of platform accelerations for the mild and moderate rear-end perturbations. The mild profile reflects the perturbation from Magnusson et al., 1999; the moderate profile has a larger magnitude and shorter time-to-peak acceleration.

Subjects were seated in a fully functional 1991 Honda Accord front passenger car seat mounted to the robot's platform (Fig. 2). Two triaxial accelerometers (Crossbow CSL04LP3 $\pm 4 \mathrm{~g}$ Module) were used; one was fixed to the subjects' foreheads to measure head accelerations, as in previous studies (Kumar et al., 2002; Kumar et al., 2004a) while the second accelerometer was mounted on the robotic platform to determine the initial onset of the platform movement. Each subject was exposed to 10 perturbation trials; 5 moderate and 5 mild, presented in random order. Subjects were provided notice of the impending perturbation using a countdown; however, subjects were unaware of the magnitude of the oncoming perturbation.

Accelerometer data were collected at a sampling frequency of $1000 \mathrm{~Hz}$ and processed using LabVIEW 7.0 (National Instruments). Data collection was initiated one second before each perturbation.

The peak vertical and anterior-posterior (A-P) head accelerations were extracted for the first moderate and mild perturbations. Statistical analysis was performed using Graphpad Software Inc., Version 4.03. Non-parametric statistics were used since the variance was not homogenous. As there is no non-parametric equivalent to two-way ANOVAs, pair-wise comparisons with paired Wilcoxon $t$ tests were used and significance was set at the 0.05 level. 


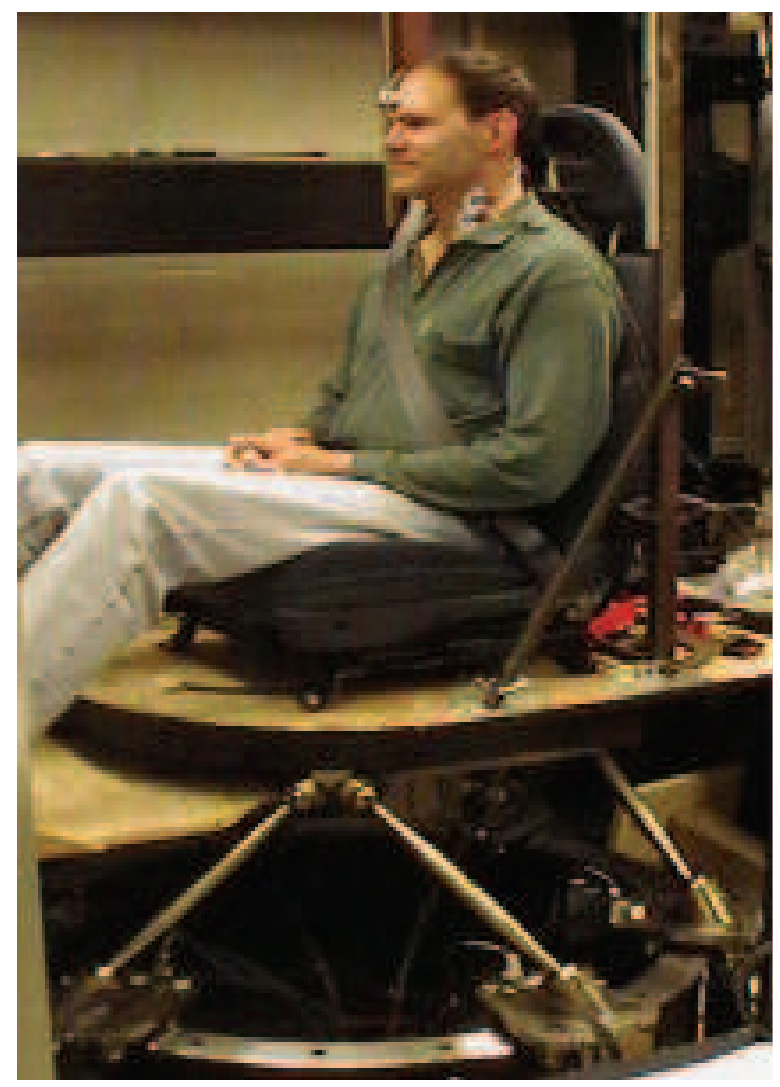

Fig. 2. Experimental setup showing a subject sitting on the automobile seat mounted to the top platform of the parallel robot. Surface EMG and head accelerometer data was collected during the perturbations with the subject secured in the car seat using the standard safety seat belt and head restraint.

\section{Results}

All subjects successfully completed the entire experimental protocol; no subjects complained of neck pain during or after the experiment. The magnitude of the head accelerations were significantly greater in the moderate perturbations compared to the mild perturbations ( $p=0.0003$ for vertical, effect size $=0.92, p=0.0003$ for horizontal head accelerations, effect size $=1.13$; Figure 2). In the mild perturbations, the magnitude of the vertical and horizontal head accelerations were not significantly different $(p>0.05)$. However, in the moderate perturbations, the magnitude of the horizontal head accelerations were significantly larger than the vertical accelerations $(p=0.0007$; effect size $=0.445)$. Both the horizontal and vertical head acceleration magnitudes were larger than the platform accelerations in all cases (refer to the horizontal lines in Figure 3). 


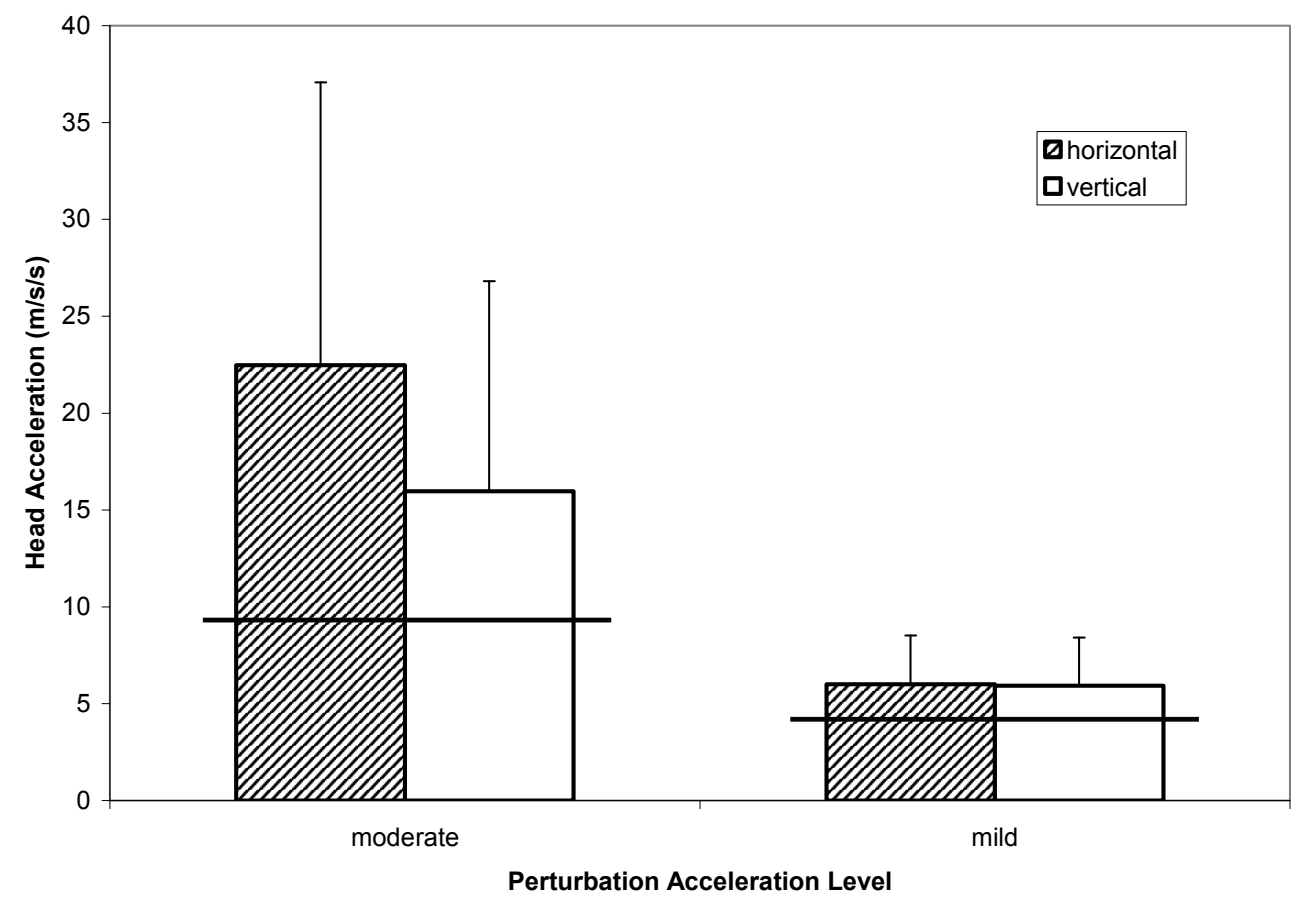

Fig. 3. Bar graph demonstrating the peak head accelerations (mean and one standard deviation) in the vertical and horizontal directions during the mild (0.41 g) and moderate $(0.94 \mathrm{~g})$ rear-end whiplash-like horizontal perturbations. The horizontal lines reflect the magnitude of the horizontal robotic platform accelerations.

\section{Discussion}

This study directly compared two different perturbation profiles, using repeated measures, to evaluate vertical and horizontal head accelerations during whiplash-like perturbations. We observed that the magnitude of the vertical head accelerations depended on the specific perturbation parameters; the horizontal and vertical acceleration magnitudes were not significantly different in the mild perturbation, but the horizontal head accelerations were significantly larger than the vertical accelerations during the moderate perturbations. These findings illustrate that human subjects have different responses to whiplash-like perturbations depending on the specific acceleration profile parameters, including peak acceleration. This finding is in contrast to one study that found that the vertical and horizontal head accelerations were highly correlated for seven different perturbation profiles (Siegmund et al., 2004), but somewhat supported by a different study that observed differences in the magnitude of the vertical head acceleration between female and male subjects (Hernandez et al., 2005). Our finding supports a recent in vitro experiment that observed that the crash pulse shape influences the peak loading and the injury tolerance levels of the neck in simulated low-speed side-collisions (Kettler et al., 2006). 
Several recent studies have reported typical and reproducible head/neck motion and acceleration patterns during perturbation testing (Dehner et al., 2007; Muhlbauer et al., 1999). It is essential to appreciate that these patterns are modulated by the specific perturbation profile. Parameters such as the time to peak acceleration, in addition to the magnitude of the acceleration and velocity, appear to influence the resulting head/neck motion. We document that the relationship between the vertical and horizontal head accelerations depend on the specific perturbation pulse; we recommend that all studies should publish their perturbation pulses to aid in comparisons between studies.

We observed that horizontal platform perturbations led to both vertical and horizontal head accelerations. However, our accelerometer measurements were influenced by the location of the accelerometer (forehead in this experiment, similar to other research studies c.f. Kumar et al. (2002) and (2004a)). We have subsequently performed testing to evaluate the differences in accelerometer measurements between mounting the accelerometer on the forehead and temple, since the temple location is closer to the center of mass of the head (Muhlbauer et al., 1999). These tests revealed that the peak horizontal forehead accelerations were approximately $16 \%$ less, and the vertical forehead accelerations $38 \%$ greater, than the peak temple accelerations. These differences arise since the forehead accelerations are also sensitive to rotational accelerations of the head, and are similar to the $16 \%$ changes in peak acceleration between mounting accelerometers on the top of the head compared to the forehead (Mills \& Carty, 2004). Nevertheless, the fact that we observed systematic differences in forehead accelerations with different perturbation profiles remains and indicates that differences would also be present for temple or head center of mass linear and/or angular accelerations; the specific features of the perturbation profile, such as the peak acceleration, influence the head acceleration responses. Another limitation of this study was that the peak acceleration of the perturbation profile was comparatively quite low. However, it is important to note that these perturbation profiles produced head accelerations and neck muscle activation patterns similar to previous experiments investigating human responses to whiplash-like perturbations (Severy et al., 1955; Magnusson et al., 1999; Siegmund et al., 2003) and that the use of a parallel robot permitted more precise control over the motion patterns than alternative testing approaches.

Clearly there is additional potential for parallel robots in this area; although some researchers have used linear sleds to simulate offset collisions by orienting the subject at an angle to the direction of sled travel (Kumar et al., 2004b), as $6 \mathrm{df}$ mechanisms, parallel robots could be programmed to move in three-dimensional space to reflect offset collisions more realistically. We are currently undertaking research projects in which we are applying concurrent vertical and horizontal perturbations, and a second study in which we are evaluating different perturbation directions.

\section{Conclusions}

The level of the perturbation acceleration influences the resulting acceleration of the head, in both the vertical and horizontal directions. A parallel robotic platform facilitated this research by enabling feedback-controlled motion for the perturbations. 


\section{Acknowledgements}

The parallel robot was purchased by a grant from the Canadian Foundation for Innovation, and funding for this study was provided by a grant from the AUTO21, one of the Canadian Networks of Centres of Excellence.

\section{References}

Brault, J.R., Wheeler, J.B., Siegmund, G.P., \& Brault, E.J. (1998). Clinical response of human subjects to rear-end automobile collisions. Archives of Physical Medicine and Rehabilitation, Vol. 79, pp. 72-80, ISSN 0003-9993.

Castro, W.H.M., Meyer, S.J., Becke, M.E.R., Nentwig, C.G., Hein, M.F., Ercan, B.I. et al. (2001). No stress - no whiplash? Prevalence of "whiplash" symptoms following exposure to a placebo rear-end collision. International Journal of Legal Medicine, 114, pp. 316-322, ISSN 0937-9827.

Choi, H. \& Vanderby, R. (1999). Comparison of biomechanical human neck models: Muscle forces and spinal loads at C4/5 level. Journal of Applied Biomechanics, Vol. 15, pp. 120-138, ISSN 1065-8483.

Dehner, C., Elbel, M., Schick, S., Walz, F., Hell, W., \& Kramer, M. (2007). Risk of injury of the cervical spine in sled tests in female volunteers. Clinical Biomechanics, Vol. 22, pp. 615-622, ISSN 0268-0033.

Hernandez, I.A., Fyfe, K.R., Heo, G., \& Major, P.W. (2005). Kinematics of head movement in simulated low velocity rear-end impacts. Clinical Biomechanics, Vol. 20, pp. 10111018, ISSN 0268-0033.

Hynes, L.M. \& Dickey, J.P. (2008). The rate of change of acceleration: Implications to head kinematics during rear-end impacts. Accident Analysis and Prevention, In Press, ISSN 0001-4575.

Kaneoka, K., Ono, K., Inami, S., \& Hayashi, K. (1999). Motion analysis of cervical vertebrae during whiplash loading. Spine, Vol. 24, pp. 763-769, ISSN 0362-2436.

Kettler, A., Fruth, K., Claes, L., \& Wilke, H.J. (2006). Influence of the crash pulse shape on the peak loading and the injury tolerance levels of the neck in in vitro low-speed side-collisions. Journal of Biomechanics, Vol. 39, pp. 323-329, ISSN 0021-9290.

Kullgren, A., Krafft, M., Nygren, A., \& Tingvall, C. (2000). Neck injuries in frontal impacts: influence of crash pulse characteristics on injury risk. Accident Analysis and Prevention, Vol. 32, pp. 197-205, ISSN 0001-4575.

Kumar, S., Ferrari, R., \& Narayan, Y. (2004a). Electromyographic and kinematic exploration of whiplash-type neck perturbations in left lateral collisions. Spine, Vol. 29, pp. 650659, ISSN 0362-2436.

Kumar, S., Ferrari, R., \& Narayan, Y. (2004b). Electromyographic and kinematic exploration of whiplash-type rear impacts: effect of left offset impact. The Spine Journal, Vol. 4, pp. 656-665, ISSN 1529-9430.

Kumar, S., Ferrari, R., \& Narayan, Y. (2005a). Kinematic and electromyographic response to whiplash loading in low-velocity whiplash impacts--a review. Clinical Biomechanics, Vol. 20, 343-356, ISSN 0268-0033.

Kumar, S., Ferrari, R., \& Narayan, Y. (2005b). Turning away from whiplash. An EMG study of head rotation in whiplash impact. Journal of Orthopaedic Research, Vol. 23, pp. 224230, ISSN 0736-0266. 
Kumar, S., Narayan, Y., \& Amell, T. (2002). An electromyographic study of low-velocity rear-end impacts. Spine, 27, pp. 1044-1055, ISSN 0362-2436.

Magnusson, M.L., Pope, M.H., Hasselquist, L., Bolte, K.M., Ross, M., Goel, V.K. et al. (1999). Cervical electromyographic activity during low-speed rear impact. European Spine Journal, 8, pp. 118-125, ISSN 0940-6719.

Mills, D. \& Carty, G. (2004). Comparative Analysis of Low Speed Live Occupant Crash Test Results to Current Literature. Proceedings of the Canadian Multidisciplinary Road Safety Conference XIV, pp. 1-14, June 2004, Ottawa, Ontario.

Muhlbauer, M., Eichberger, A., Geigl, B.C., \& Steffan, H. (1999). Analysis of kinematics and acceleration behavior of the head and neck in experimental rear-impact collisions. Neuro-Orthopedics, Vol. 25, pp. 1-17, ISSN 0177-7955.

Nightingale, R.W., Camacho, D.L., Armstrong, A.J., Robinette, J.J., \& Myers, B.S. (2000). Inertial properties and loading rates affect buckling modes and injury mechanisms in the cervical spine. Journal of Biomechanics, Vol. 33, pp. 191-197, ISSN 0021-9290.

Severy, D.M., Mathewson, J.H., \& Bechtol, C.O. (1955). Controlled automobile rearend collisions, an investigation of related engineering and medical phenomena. Canadian Services Medical Journal, Vol. 11, pp. 727-759.

Siegel, J.H., Loo, G., Dischinger, P.C., Burgess, A.R., Wang, S.C., Schneider, L.W. et al. (2001). Factors influencing the patterns of injuries and outcomes in car versus car crashes compared to sport utility, van, or pick-up truck versus car crashes: Crash Injury Research Engineering Network Study. The Journal of Trauma, Vol. 51, pp. 975990, ISSN 0022-5282.

Siegmund, G.P., Heinrichs, B.E., Chimich, D.D., DeMarco, A.L., \& Brault, J.R. (2005). The effect of collision pulse properties on seven proposed whiplash injury criteria. Accident Analysis and Prevention, Vol. 37, pp. 275-285, ISSN 0001-4575.

Siegmund, G.P., Myers, B.S., Davis, M.B., Bohnet, H.F., \& Winkelstein, B.A. (2001). Mechanical evidence of cervical facet capsule injury during whiplash: a cadaveric study using combined shear, compression, and extension loading. Spine, Vol. 26, pp. 2095-2101, ISSN 0362-2436.

Siegmund, G.P., Sanderson, D.J., \& Inglis, J.T. (2004). Gradation of Neck Muscle Responses and Head/Neck Kinematics to Acceleration and Speed Change in Rear-End Collisions. STAPP Car Crash Journal, Vol. 48, pp. 419-430, ISSN 1532-8546.

Siegmund, G.P., Sanderson, D.J., Myers, B.S., \& Inglis, J.T. (2003). Awareness affects the response of human subjects exposed to a single whiplash-like perturbation. Spine, Vol. 28, pp. 671-679, ISSN 0362-2436.

Welcher, J.B. \& Szabo, T.J. (2001). Relationships between seat properties and human subject kinematics in rear impact tests. Accident Analysis and Prevention, Vol. 33, pp. 289304, ISSN 0001-4575.

Welcher, J.B., Szabo, T.J., \& Voss, D.P. (2001). Human Occupant Motion in Rear-End Impacts: Effects of Incremental Increases in Velocity Change. SAE 2001 World Congress, pp. 241-249, Warrendale, PA, Society of Automotive Engineers, Inc, April 2001. 


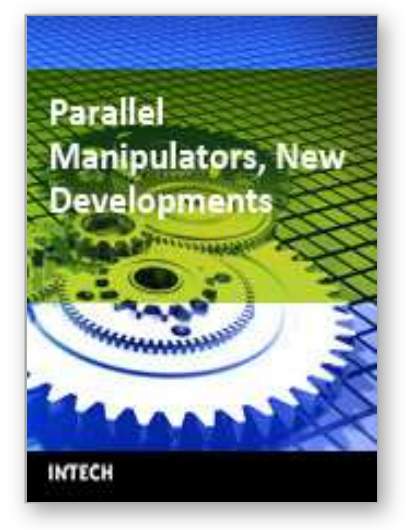

\author{
Parallel Manipulators, New Developments \\ Edited by Jee-Hwan Ryu
}

ISBN 978-3-902613-20-2

Hard cover, 498 pages

Publisher I-Tech Education and Publishing

Published online 01, April, 2008

Published in print edition April, 2008

Parallel manipulators are characterized as having closed-loop kinematic chains. Compared to serial manipulators, which have open-ended structure, parallel manipulators have many advantages in terms of accuracy, rigidity and ability to manipulate heavy loads. Therefore, they have been getting many attentions in astronomy to flight simulators and especially in machine-tool industries. The aim of this book is to provide an overview of the state-of-art, to present new ideas, original results and practical experiences in parallel manipulators. This book mainly introduces advanced kinematic and dynamic analysis methods and cutting edge control technologies for parallel manipulators. Even though this book only contains several samples of research activities on parallel manipulators, I believe this book can give an idea to the reader about what has been done in the field recently, and what kind of open problems are in this area.

\title{
How to reference
}

In order to correctly reference this scholarly work, feel free to copy and paste the following:

Loriann M. Hynes, Natalie S. Sacher and James P. Dickey (2008). Specific Parameters of the Perturbation Profile Differentially Influence the Vertical and Horizontal Head Accelerations During Human Whiplash Testing, Parallel Manipulators, New Developments, Jee-Hwan Ryu (Ed.), ISBN: 978-3-902613-20-2, InTech, Available from:

http://www.intechopen.com/books/parallel_manipulators_new_developments/specific_parameters_of_the_pert urbation_profile_differentially_influence_the_vertical_and_horizontal

\section{INTECH}

open science | open minds

\section{InTech Europe}

University Campus STeP Ri

Slavka Krautzeka 83/A

51000 Rijeka, Croatia

Phone: +385 (51) 770447

Fax: +385 (51) 686166

www.intechopen.com

\section{InTech China}

Unit 405, Office Block, Hotel Equatorial Shanghai

No.65, Yan An Road (West), Shanghai, 200040, China

中国上海市延安西路65号上海国际贵都大饭店办公楼 405 单元

Phone: +86-21-62489820

Fax: $+86-21-62489821$ 
(C) 2008 The Author(s). Licensee IntechOpen. This chapter is distributed under the terms of the Creative Commons Attribution-NonCommercialShareAlike-3.0 License, which permits use, distribution and reproduction for non-commercial purposes, provided the original is properly cited and derivative works building on this content are distributed under the same license. 